\title{
Morphological separation of host adapted taxa within the Hyalopterus pruni complex (Hemiptera: Aphididae)
}

\author{
Konstantinos D. POULIOS, John T. MARGARITOPOULOS* and John A. TSITSIPIS \\ Laboratory of Entomology and Agricultural Zoology, Department of Agriculture, Crop Production and Rural Environment, \\ University of Thessaly, Fytokou Str., 384 46, Nea Ionia, Magnesia, Greece
}

\begin{abstract}
Key words. Aphididae, Hyalopterus pruni, H. amygdali, mealy plum aphid, mealy peach aphid, host adaptation, Prunus, morphology, canonical variates analysis
\end{abstract}

\begin{abstract}
Morphometric variation of individuals in field collected samples of the Hyalopterus pruni complex from various Prunus species and regions of Greece was examined, to determine whether this variation is correlated with the host-trees from which the aphids originated. Morphometric data for 13 parameters of aphids from 74 field samples (760 adult apterae) were analysed by canonical variates analysis (CVA). Each sample was collected from a different tree and consisted of individuals from 2-3 neighbouring leaves from the same branch. Each field sample was used as a grouping factor in the CVA. The analysis produced three clusters corresponding to the taxa indicated by previous studies using allozyme markers (i.e., Hyalopterus pruni on apricot, blackthorn, plum and cherry, $H$. amygdali $\mathrm{A}$ on almond and $H$. amygdali $\mathrm{B}$ on peach). The separation was independent on the geographical origin of the samples. However, host associations within the complex were not absolute, and in particular the samples from apricot appeared to include both $H$. pruni and $H$. amygdali A. In contrast to previous views, the present study showed that the taxa have their own distinct morphology. Lastly, discriminant functions for separating the adult apterae of the taxa are given.
\end{abstract}

\section{INTRODUCTION}

The adaptation of animals to different habitats or resources, in other words ecological specialization, and the possibility that this enhances population divergence and leads to speciation is of contemporary interest (Futuyma \& Moreno, 1988; Bush, 1994; Thompson, 1994; Schluter, 2001; Via, 2001; Berlocher \& Feder, 2002). For herbivorous insects, there is much data demonstrating ecological specialization after host shifts. They include species complexes, biotypes, host-races, or subspecies, which in many cases overlap in geographical distribution but differ in host plant affiliations (Mopper \& Strauss, 1997). Among phytophagous insects, aphids provide important examples of such specialization and may be good candidates for sympatric speciation (Dixon, 1998). Aphids show a high degree of host specificity, with $99 \%$ of all species constrained to one or a few closely related plant species (Eastop, 1973) and many polyphagous aphid pests consist of two or more subspecific taxa with different host-plant affiliations (Blackman, 1990; Blackman \& Eastop, 2006).

From a practical point of view, studies on hostspecialized subspecific taxa or closely related species, often morphologically indistinguishable, improve our knowledge of their ecology and provide valuable information for optimizing crop protection programs. Fundamental, however, for both practical and theoretical purposes is the development of tools for correctly identifying insect taxa. Various molecular tools and analytical methods (for review see Loxdale \& Lushai, 1998; Sunnucks, 2000) are now available for studying such host-specialized insects.
Their application, however, fails sometimes to provide reliable diagnostic markers for host-specialized subspecific aphid taxa (e.g. Clements et al., 2000; Raymond et al., 2001). The lack of detectable genetic differentiation is expected, especially in cases of rapid speciation via processes known as reinforcement, which can occur through changes at very few loci (Coyne \& Orr 1989; Liou \& Price 1994; Johnson et al., 1996; Barton, 2000). Nevertheless, one limitation of molecular tools is the requirement for specialized equipment and laboratories. On the other hand, morphotaxonomy, if it provides reliable discrimination of taxa, can be a widespread tool among applied entomologists.

The mealy aphids of the Hyalopterus pruni complex (Hemiptera: Aphididae) provide a typical example of closely related taxa that exhibit different host plant affiliations. These aphids produce a bisexual generation on various Prunus species (Rosaceae) (primary hosts) in autumn, which alternates with several unisexual (all female) generations produced parthenogenetically on Prunus species in spring and on secondary hosts, such as Phragmites communis Trin. and Arundo donax L. (Poaceae), during summer. In tropical Africa, populations on Phragmites reproduce only parthenogenetically (Blackman \& Eastop, 2000). Two species are currently placed within the genus Hyalopterus, i.e., Hyalopterus pruni (Geoffroy) and Hyalopterus amygdali (Blanchard). The specific status of these two taxa, however, is unclear according to some authors (e.g. Stroyan, 1984). The main primary hosts of $H$. pruni are plum, Prunus domestica L., and apricot, Prunus armeniaca L., while peach, Prunus

\footnotetext{
* Corresponding author; e-mails: johnmargaritopoulos@yahoo.com; jmarg@uth.gr
} 
TABLE 1. Information on the host-tree, collection date, locality and number of field samples and individuals of the Hyalopterus pruni complex measured.

\begin{tabular}{|c|c|c|c|c|}
\hline Host & Locality & $\mathrm{N}$ & $\mathrm{n}$ & Collection date \\
\hline \multirow[t]{4}{*}{ Prunus armeniaca (apricot) } & Volos (ECG) & 4 & 42 & 15.v.05 \\
\hline & Agioi Apostoloi (CG ) & 3 & 28 & 11.-16.v.05 \\
\hline & Meliki (NG) & 4 & 41 & 13.v.05 \\
\hline & Platanidia (ECG) & 4 & 41 & 31.v.05 \\
\hline \multirow[t]{3}{*}{ Prunus cerasifera (cherry plum) } & Agioi Apostoloi (CG) & 11 & 111 & 4.v.-3.vi.05 \\
\hline & Volos (ECG) & 2 & 17 & 15.v.05 \\
\hline & Kalambaka (CG) & 1 & 12 & 16.vi.05 \\
\hline Prunus domestica (plum) & Agioi Apostoloi (CG) & 1 & 11 & 3.vi.05 \\
\hline Prunus spinosa (blackthorn) & Stagiades $(\mathrm{CG})$ & 7 & 75 & 30.vi.05 \\
\hline \multirow[t]{5}{*}{ Prunus dulcis (almond) } & Agios Vlasios (ECG) & 1 & 11 & 9.v.05 \\
\hline & Zarko (CG) & 8 & 79 & 21.v.05 \\
\hline & Volos (ECG) & 6 & 63 & 10.v.05 \\
\hline & Agii Apostoloi (CG) & 2 & 23 & 3.vi.05 \\
\hline & Meliki (NG) & 1 & 12 & 15.v.05 \\
\hline \multirow[t]{5}{*}{ Prunus persica (peach) } & Volos (ECG) & 2 & 18 & 10.v.05 \\
\hline & Lechonia (ECG) & 12 & 134 & 12,13.v.05 \\
\hline & Agios Lavrentios (ECG) & 1 & 11 & 12.v.05 \\
\hline & Heraklion, Crete & 3 & 21 & 10.v.05 \\
\hline & Chania, Crete & 1 & 11 & 10.v.05 \\
\hline
\end{tabular}

$\mathrm{N}=$ number of field samples (each sample consisted of aphids from 2-3 neighbouring leaves on the same branch) and $\mathrm{n}=$ number of adult apterae measured. $\mathrm{NG}=$ northern Greece, $\mathrm{ECG}=$ eastern central Greece, $\mathrm{CG}=$ central Greece .

persica L., and almond, Prunus dulcis (Mill.), are colonised by $H$. amygdali. Based on allozyme data from Italian populations, Spampinato et al. (1988) suggested that $H$. pruni is genetically distinct and $H$. amygdali is heterogeneous. This was confirmed by an extensive study of Italian and Sicilian populations of the taxa using allozyme markers (Mosco et al., 1997). These authors detected three taxa: the genetically close $H$. pruni and $H$. amygdali $\mathrm{A}$ and $H$. amygdali $\mathrm{B}$. Hyalopterus pruni was collected from plum, apricot, and less frequently from blackthorn, Prunus spinosa L., cherry plum, Prunus cerasifera (Ehrh.), and Pissard's plum, Prunus pissardi (Hort.), while $H$. amygdali $\mathrm{A}$ and the $H$. amygdali $\mathrm{B}$ were found on almond and peach, respectively, and occasionally share primary hosts. These authors report that these three taxa are isolated in the field, with no gene exchange. This was also supported by observations made by Basky \& Szalay-Marszó (1987) in cross-host transfer and mating trials involving $H$. pruni from plum and $H$. amygdali s.l. from peach.

Given these findings it is of interest to know whether these three distinct taxonomic entities within the $H$. pruni complex exhibit consistent morphological differences. Associations between morphology, host-plant affiliation or genetic properties occur in various closely-related aphid taxa, e.g. Amphorophora spp. (Blackman et al., 1977), Myzus persicae group (Blackman, 1987; Margaritopoulos et al., 2000), Aphis gossypii Glover (Margaritopoulos et al., 2006) and Euceraphis spp. (Blackman \& De Boise, 2002). Previous reports in the literature suggest that $H$. pruni and $H$. amygdali differ from each other in the length-width ratio of the cornicle of adult apterae and the number of sensoria on the third antennal segment of alatae (Börner \& Heinze, 1957; Eastop, 1966). However, Basky \& Szalay-Marszó (1987), who examined a large number of individuals, found these traits unsuitable for the discrimination of these two taxa.

In the present study many morphological characters in aphids of the $H$. pruni complex collected in the field from various Prunus species and regions of Greece were examined and a multivariate morphometric technique, specifically canonical variates analysis (CVA), was used to determine whether the three taxa can be reliably discriminated morphologically.

\section{MATERIAL AND METHODS}

The study was based on field samples collected from various Prunus trees from different regions in mainland Greece and Crete (Table 1). The samples were collected mostly from orchards of about 0.5-2 ha. Those from P. spinosa, however, were collected from trees found in the hedges around orchards, field crops or non cultivated areas such as grasslands. Each sample was collected from a different tree and consisted of the aphids on 2-3 neighbouring leaves, on the same branch. The samples were put separately in self-sealing plastic bags, with a piece of paper towel to reduce moisture. Bags were transferred to the laboratory in insulated plastic containers, containing frozen ice packs. The aphids were inspected to determine whether they were parasitized and 10-20 unparasitized adult apterae from each sample were put in tubes filled with one part lactic acid $(75 \% \mathrm{w} / \mathrm{w})$ and three parts ethanol $(95 \%)$ until they could be permanently mounted on slides. Whole body mounts on microscope slides were prepared for measurement according to the method described by Blackman \& Eastop (2000). 
TABLE 2. Canonical coefficients (standardized) and percentage of total variance accounted for the vectors that contributed to the separation of the three taxa within the Hyalopterus pruni complex.

\begin{tabular}{ccccc}
\hline \multirow{2}{*}{ Characters } & \multicolumn{2}{c}{ First CVA (Fig. 1) } & \multicolumn{2}{c}{ Second CVA (Fig. 2) } \\
\cline { 2 - 5 } CV1 & 0.715 & -0.530 & -0.882 & -0.639 \\
$\mathrm{ff}$ & 0.137 & -0.119 & -0.136 & -0.225 \\
$\mathrm{hf}$ & -0.235 & -0.802 & -0.684 & 0.409 \\
$\mathrm{ft}$ & -0.118 & 0.154 & 0.366 & 0.282 \\
$\mathrm{mt}$ & -0.699 & 0.877 & 0.833 & 0.146 \\
$\mathrm{ht}$ & -0.345 & 0.132 & 0.376 & -0.974 \\
$\mathrm{ant}$ III & 0.184 & 0.755 & 0.534 & 0.037 \\
base VI & 0.166 & 0.214 & 0.151 & -0.041 \\
$\mathrm{pt}$ & -0.505 & -0.525 & -0.183 & 0.750 \\
$\mathrm{lc}$ & 0.705 & -0.108 & -0.323 & -0.162 \\
ls & -0.226 & -0.073 & 0.095 & 0.515 \\
$\mathrm{ht} 2$ & 0.648 & 0.170 & -0.043 & -0.105 \\
urs & -0.094 & 0.368 & 0.372 & 0.218 \\
\% of total variance & 40.6 & 22.0 & 47.7 & 12.2 \\
Correlation with the size index & $\mathrm{R}=-0.056, \mathrm{P}<0.63$ & $\mathrm{R}=0.512, \mathrm{P}<0.01$ & $\mathrm{R}=-0.116, \mathrm{P}<0.46$ & $\mathrm{R}=-0.451, \mathrm{P}<0.02$ \\
\hline
\end{tabular}

$\mathrm{ff}$ - length of fore femur; $\mathrm{mf}$ - length of middle femur; $\mathrm{hf}$ - length of hind femur; $\mathrm{ft}$ - length of fore tibia; $\mathrm{mt}$ - length of middle tibia; ht - length of hind tibia; ant III - length of the third antennal segment; base VI - length of the base of the sixth antennal segment; $\mathrm{pt}$ - length of the terminal process of the sixth antennal segment; lc - length of cauda; ls - length of siphunculi; ht 2 - length of the second segment of hind tarsus; urs - length the ultimate rostral segment.

About 10 specimens (minimum 4, maximum 12) from each field sample were measured. The material studied consisted of 74 field samples consisting of 760 individuals. The following 13 characters were measured on each specimen: lengths of tibia and femur of the fore, middle and hind leg (ft, $\mathrm{mt}$, ht, $\mathrm{ff}, \mathrm{mf}$ and $\mathrm{hf}$, respectively), length of the second segment of hind tarsus (ht2), length of cauda (lc), length of the third antennal segment (ant III), lengths of the base and terminal process of the sixth antennal segment (base VI and pt, respectively), length of siphunculi (ls) and length of the ultimate rostral segment (urs) (for details of measurements see Ilharco \& van Harten, 1987). All measurements were made using a phase contrast microscope (Leica DRMB, Leica Mikroskopie und System GmBH, Germany) fitted with a calibrated micrometer eyepiece.

To determine whether any host-related differences exist between the field samples, the data were submitted to a canonical variates analysis (CVA), without prior transformation (Krzanowski, 1990). Each sample was treated as one group in the analysis. The analysis, therefore, is completely objective as no information is included about the potential interrelationships of the samples (Blackman, 1992). A common criticism (Thorpe, 1983), therefore, of the use of CVA in systematic studies is overcome. Correlations between the vectors provided by CVA and a general size index (= sum of the lengths of all characters measured) were used to determine the relative contributions of genetic and environmental components in the morphological separation among samples (Blackman \& Spence, 1994). CVA is believed to be sensitive to heteroscedasticity (different within-group variances), and samples with heterogeneous variances could be misplaced or could affect the whole analysis (Thorpe, 1983). The homogeneity of variance in field samples was therefore determined using Brown \& Forsythe's test (Brown \& Forsythe, 1974)

In addition, the phenotypic relationships among populations from different host-trees were examined using UPGMA (Unweighted Pair Group Method with Arithmetic Mean) hierarchical cluster analysis (Sneath \& Sokal, 1973) based on Mahala- nobis' distances. Fisher's linear discriminant functions (LDFs) (Fisher, 1936) were used to examine the correct classification of individual aphids into the well defined groups revealed by CVA. A stepwise method was used to exclude variables that contributed little to the separation of the groups. SPSS ver.10 (SPSS Inc., 1999) statistical package was used for CVA and LDFs, while STATISTICA 6.0 (StatSoft Inc., 2001) was used for hierarchical cluster analysis and basic statistics.

\section{RESULTS}

In the CVA of all 74 samples, the first two CVs accounted for $62.6 \%$ of the total variance (Table 2 ) and

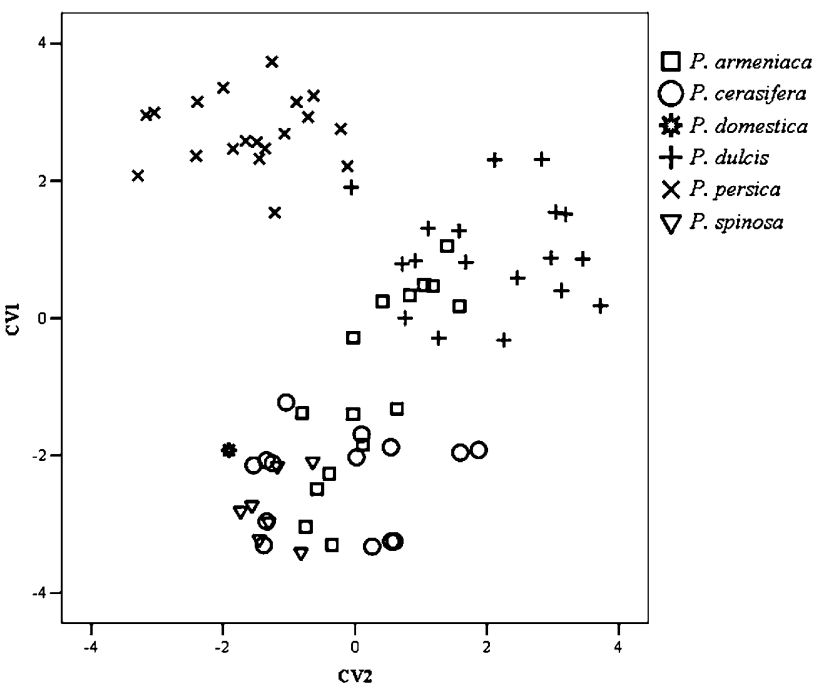

Fig. 1. Plot of mean scores of the first two canonical variates for all the 74 samples of the Hyalopterus pruni complex examined in this study. 


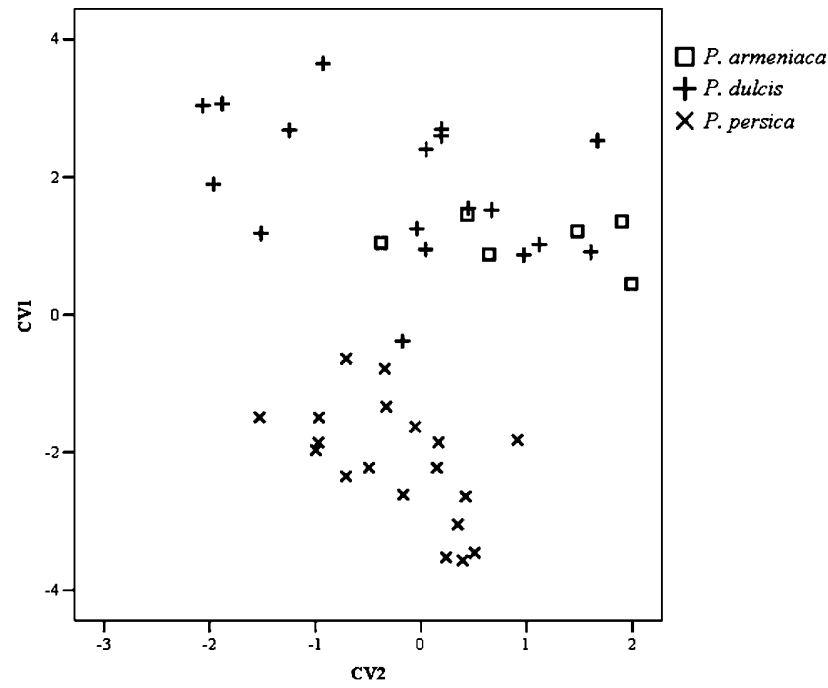

Fig. 2. Plot of mean scores of CV1 and CV2 for 43 samples of the Hyalopterus pruni complex. The six samples from apricot were allocated to the almond group in the first CVA (Fig. 1).

separated the samples into three clusters (Fig. 1). The first contained the samples from peach, the second those from almond and the third the aphids from other Prunus species (i.e., apricot, blackthorn, plum and cherry plum). The separation is mainly on the basis on the mean scores of the samples on CV1. CV2 is completely neutral for $H$. pruni (scores all around zero) but gives maximum differentiation between the other two taxa (values on each side of zero), with a contribution also from CV1. The separation, however, between the three major groups was not absolute since one sample from almond was located near the group of peach samples and six samples from apricot were mixed with those from almond. CV1 was not correlated with a general size index. CV2, however, was significantly, but not highly, size-correlated, probably reflecting some contribution from environmental factors (Table 2). The morphometric characters with the highest
CV1 coefficients, i.e. those contributing significantly to the separation of the three groups, were $\mathrm{ff}, \mathrm{mt}, \mathrm{pt}, \mathrm{lc}$ and ht2 (Table 2).

Using the Brown \& Forsythe's test (1974), variance was found to be homogenous among samples for all the morphological characters measured. Coefficients of variation were also calculated for all characters and samples used in the analysis, i.e. 962 cases ( 74 samples X 13 characters). In most cases (76.4\%) the coefficient of variation (CV\%) was less than $6 \%$ and in $22.5 \%$ of the cases it was $6-10 \%$. Only in $0.3 \%$ of the cases was the coefficient high, i.e. $22.0-26.0 \%$. These results showed that withinsamples variance was not high and therefore the structure of the data is unlikely to have a significant effect on CVA. Other attempts, using combinations of CV1 with other canonical vectors, did not give a better separation of the three groups.

Two additional analyses were performed to see if a better between-group separation could be achieved, by examining only two groups in each CVA. This procedure increases the resolving power of the method (Blackman, 1992). The second CVA, therefore, was performed without all but the samples from almond and peach Prunus species, which were found the most distinct ones. The six samples from apricot, which were mixed with the aphids from almond in the previous analysis (Fig. 1), were included in this CVA. The plot of CV1 vs. CV2 (non-significant and low size correlation, respectively) (Fig. 2), accounted for $59.9 \%$ of the total variation in the data (Table 2) and clearly separated the aphids into two groups. All the peach samples were located in one group. However, the six samples from apricot were not differentiated from those from almond and located in the second group, and the one sample from almond was again located near the aphids from peach, as in the previous CVA (Fig. $1)$. The two groups were separated by the scores of the samples on CV1. The morphological characters with the highest CV1 coefficients were ff, hf, $\mathrm{mt}$ and ant III. Only,
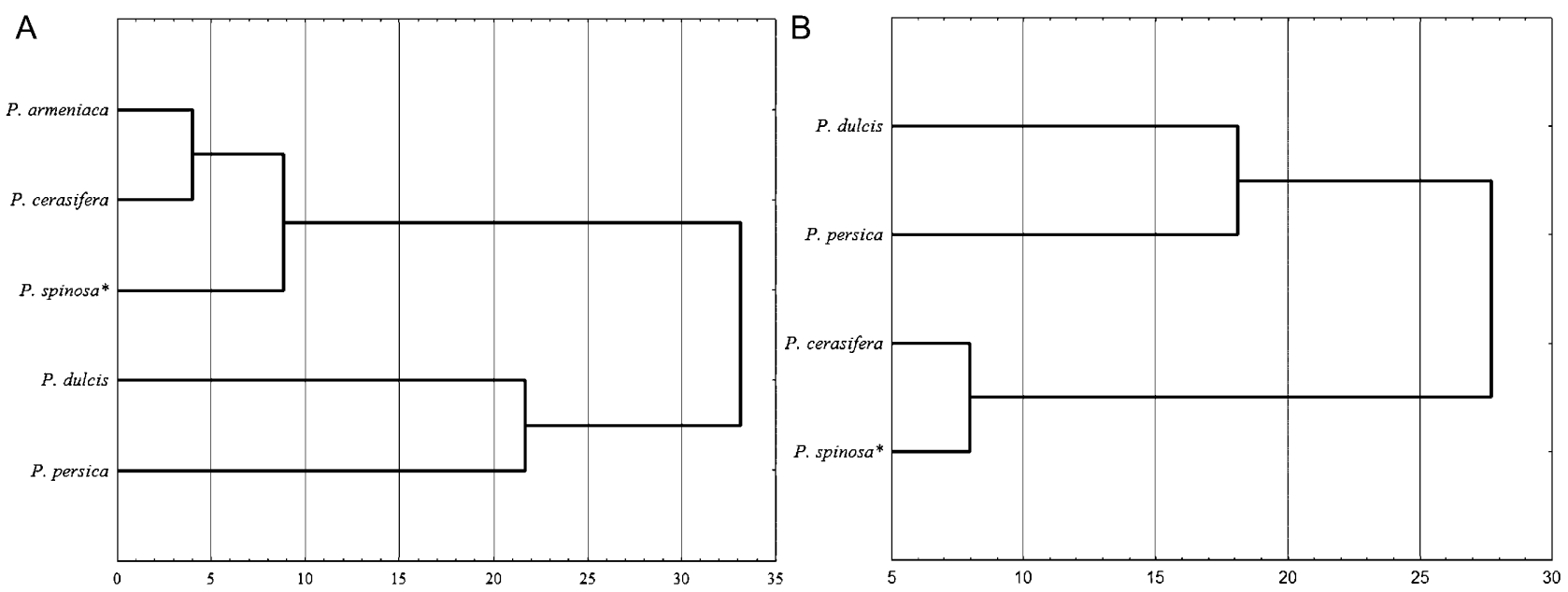

Fig. 3. UPGMA dendrograms based on Mahalanobis' distances between samples of the Hyalopterus pruni complex from different host-trees (*one sample from $P$. domestica is included). A - samples from all host-trees. Six samples from apricot were allocated to the almond group according to the results of the CVAs (Fig. 1). B - all samples from apricot were excluded. 
TABLE 3. Fisher's linear discriminant functions (LDFs) for discriminating Hyalopterus pruni from H. amygdali A \& B and H. amygdali $\mathrm{A}$ from $H$. amygdali $\mathrm{B}$.

\begin{tabular}{|c|c|c|c|c|c|}
\hline \multirow{2}{*}{ Characters } & \multicolumn{2}{|c|}{ LDFs } & \multirow{2}{*}{ Characters } & \multicolumn{2}{|c|}{ LDFs } \\
\hline & H. pruni & H. amygdali $\mathrm{A} \& \mathrm{~B}$ & & H. amygdali $\mathrm{A}$ & H. amygdali $\mathrm{B}$ \\
\hline $\mathrm{ff}$ & 58.1 & 124.3 & $\mathrm{ff}$ & 446.7 & 545.3 \\
\hline $\mathrm{mt}$ & -34.9 & -70.8 & $\mathrm{mf}$ & -115.8 & -86.5 \\
\hline hf & -157.5 & -212.1 & $\mathrm{mt}$ & -47.5 & -130.7 \\
\hline ht & 19.2 & 2.3 & hf & -25.5 & 14.5 \\
\hline ant III & -138.0 & -87.7 & ant III & -165.5 & -207.7 \\
\hline base VI & 704.5 & 827.0 & lc & 585.2 & 666.4 \\
\hline $\mathrm{pt}$ & 305.5 & 241.9 & ls & 100.6 & 38.8 \\
\hline lc & 678.4 & 829.3 & urs & 7825.3 & 7436.2 \\
\hline ls & 422.4 & 363.4 & Constant & -434.6 & -412.0 \\
\hline ht 2 & 2675.8 & 2998.3 & & & \\
\hline Constant & -360.0 & -398.2 & & & \\
\hline
\end{tabular}

$\mathrm{ff}$ - length of fore femur; $\mathrm{mt}$ - length of middle tibia; $\mathrm{mf}$ - length of middle femur; hf - length of hind femur; ht - length of hind tibia; ant III - length of the third antennal segment; base VI - length of the base of the sixth antennal segment; pt - length of the terminal process of the sixth antennal segment; lc - length of cauda; 1s - length of siphunculi; ht 2 - length of the second segment of hind tarsus; urs - length of the ultimate rostral segment. Taxa according to Mosco et al. (1997). H. pruni - samples from apricot, plum, cherry plum and blackthorn. H. amygdali $\mathrm{A}$ - samples from almond; H. amygdali $\mathrm{B}$ - samples from peach.

two of these characters contributed significantly to the separation of the three groups in the previous analysis (Table 2). Thus, the second CVA resulted in a CV1 that differed from that of the previous analysis. Other combinations of CV1 with other vectors did not provide a better separation. A third CVA was also performed in which the samples from peach were excluded. However, this analysis did not improve the separation between the two groups (almond vs. all but peach and almond Prunus species) compared to the first CVA (Fig. 1), regardless of the combination of canonical vectors used (results not shown).

The previous analyses suggest that the taxa from almond can also colonize apricot. An UPGMA cluster analysis that does not take into account the CVA allocation of six of the samples from apricot to the almond group is unlikely to give a result that correctly reflects the phenotypic relationships between taxa. The UPGMA analysis, with the six samples from apricot incorporated as members of the almond group, revealed two major clusters. The first contained the samples from apricot, blackthorn, plum, and cherry plum and the second those from almond and peach (Fig. 3a). Similar clustering was produced when either the six aforementioned samples (tree not shown) or all the samples from apricot were not used in the analysis (Fig. 3b).

Given that the CVA revealed three major groups (taxa) within the $H$. pruni complex, a final step in the analysis was to evaluate the separation of the groups at the level of individual aphids by calculating Fisher's linear discriminant functions (LDFs). The LDFs were calculated for pairs of putative taxa. The apricot samples were allocated to the taxa indicated by CVA. Particularly, LDFs were calculated for $H$. pruni (samples from plum, cherry plum, blackthorn and apricot) versus $H$. amygdali A \& B (sam- ples from almond and peach along with the six samples from apricot allocated to the almond group by CVA), and separately for $H$. amygdali B (samples from peach) versus $H$. amygdali A (samples from almond and the aforementioned six samples from apricot) (Table 3). The percentage of correctly classified individuals in the first and the second pair of LDFs was $94.3 \%$ and $92.5 \%$, respectively.

\section{DISCUSSION}

The results of the present study revealed the existence of three morphologically differentiated groups within the H. pruni complex in Greece. The first consisted of the samples from peach, the second those from almond and the third the aphids from other Prunus species, such as: apricot, blackthorn, plum and cherry plum. The morphological separation did not involve the examination of single characters, which has often proved ineffective (e.g. Basky \& Szalay-Marszó, 1987), but was based on CVA, a technique that compares the correlations between numerous characters. It has proved to be a powerful tool for resolving taxonomic problems associated with closelyrelated aphid taxa (e.g. Blackman et al., 1977; Blackman, 1987; Brown \& Blackman, 1994; Margaritopoulos et al., 2006). This technique can effectively separate environmental from genetic components of variance and even distinguish between different genotypes, as has been demonstrated using aphid clones of closely related species reared under laboratory conditions (Blackman \& Spence, 1994). In addition, the technique has proved effective when applied to samples from field populations (e.g. Blackman \& De Boise, 2002; Margaritopoulos et al., 2006).

The separation obtained in the present study might also reflect some environmental influences in addition to the 
genetic differences between the three groups. Temperature can affect both isometric and allometric growth in aphids (Blackman \& Spence, 1994). Also, the species and the physiological condition of the host plant can significantly affect aphid morphology (Moran, 1986; Wool \& Hales, 1997; Dixon, 1998; Margaritopoulos et al., 2000). Although environmental factors may have contributed to the separation of the field samples, the morphological differences are likely to reflect mostly host-related genetic differences. This is supported by the fact that the separation was based on vectors with a rather strong genetic component, i.e. those that show a low or non-significant correlation with the size index. This index is known to be strongly affected by environmental factors (Blackman \& Spence, 1994). In addition, low CV\% values were observed for each morphological character. Low values were also calculated (4-9\%) when the samples were pooled in the three groups revealed by the CVA (i.e., peach, almond and other Prunus species). According to Soulè \& Couzin-Roudy (1982) there should be a negative correlation between $\mathrm{CV} \%$ and estimates of heritability of morphological traits. The relatively low $\mathrm{CV} \%$ values found might suggest a high heritability and a proportionally lower contribution of environmentally determined variance to the morphological variability of each character.

To interpret taxonomic relationships within an aphid group based only on morphological variation may be misleading. However, the present study targets taxa in which there is already evidence of host-associated genetic variation and reproductive isolation (Spampinato et al., 1988; Mosco et al., 1997). Generally, the three host-associated morphologically distinct groups found accord with the results of Mosco et al. (1997). The morphological separation between the three groups found in the present study was based on the examination of different aphid genotypes. Each aphid sample was collected from a different tree, primary host of the species, and therefore originated from a different sexually produced egg. In addition, the clustering was independent of the geographical origin of the aphid samples. This suggests that abiotic factors such as temperature, which differs among regions, might not have a significant effect on the morphological separation of the three taxa. The separation, however, was not complete. One almond sample was located near the group consisting of samples from peach. In addition, six samples from apricot were mixed with those from almond in all CVAs performed. This could be attributed to two factors, hybridization between taxa or an imperfect host association, especially by $H$. amygdali A. Mosco et al. (1997) found no hybrids between $H$. pruni and either of the two $H$. amygdali taxa and only a few were detected between $H$. amygdali $\mathrm{A}$ and $H$. amygdali $\mathrm{B}$. These authors also found "wrong choice" of host by both $H$. amygdali A and $H$. amygdali $\mathrm{B}$ in regions where the preferred host-trees of these taxa were absent. Basky \& Szalay-Marszó (1987) in mating experiments found that males of $H$. pruni from plum never copulated with mating females of $H$. amygdali from peach (probably taxa B) and vice versa. This might suggest that, as the divergence within $H$. pruni complex occurred in the Pleistocene (Mosco et al., 1997), these taxa have had possibly enough time to become reproductively isolated and develop prezygotic reproductive isolation mechanisms. It seems likely, therefore, that the cases of misclustering observed in the present study indicate an imperfect host association by some genotypes, although more research is needed, especially involving DNA technology, before conclusions can be drawn.

Nevertheless, the application of a multivariate morphometric analysis in the present study changed our view, based on less discriminatory techniques (e.g. Basky \& Szalay-Marszó, 1987), that the members of the $H$. pruni complex are poorly morphological differentiated. The analysis has shown clearly that the three members of the complex represent distinct morphological entities. Our findings also add to the suggestion of Mosco et al. (1997) that the three taxa are reproductively isolated in the field and should be considered as three distinct biological species. This was proposed a long time ago by Börner \& Heinze (1957). The hypothesis for a Pleiostocene divergence for the $H$. pruni complex (Mosco et al., 1997) means the taxa had enough time to diversify and develop morphological differences.

The best approach to establish the identity of new samples involves measuring many characters on a series of specimens, incorporating them into an existing data base and performing CVA. This procedure, however, is rather laborious and may be impracticable. Thus, an attempt was made in the present study to develop linear discriminant functions (LDFs), based on a reduced number of morphological characters, for a two-step identification of the three taxa. The LDFs described here classified individual apterae, with a relatively low misclassification error (6-7\%). However, LDFs might discriminate less satisfactorily when applied to new samples, as found in other aphid species (e.g., Rhopalosiphum maidis (Fitch), Blackman \& Brown, 1991). Therefore, the development of more reliable functions requires the examination of a wider range of specimens, preferably of different geographical origin. Until this is done, the LDFs reported here can help to distinguish specimens of the three taxa. With further work, it may also be possible to produce LDFs for alatae identification, since this form is likely to show differences paralleling those found in apterae. Lastly, an application of multivariate morphometric analysis on the generations of these aphids living on secondary host plants combined with some performance and behavioural trials will give further insights in the evolution of the members of the $H$. pruni complex and might also clarify whether there are any specific secondary host associations, for example with species of Arundo or Phragmites.

ACKNOWLEDGEMENTS. The study was supported by funds of the program from Postgraduate Studies (PSP) of the School of Agricultural Sciences of University of Thessaly "Modern Systems of Agricultural Development in the Mediterranean Domain, with Emphasis on Sustainable Production and Usage of Novel Technologies". The authors thank K.D. Zarpas for com- 
menting on drafts of this manuscript and K. Tsamantani for technical assistance. The authors also thank R.L. Blackman for valuable constructive comments and suggestions that improved the quality of the paper.

\section{REFERENCES}

BARTON N. 2000: The rapid origin of reproductive isolation. Science 290: 462-463.

BASKY Z. \& SzAlay-Marszó L. 1987: Study of isolation mechanisms in the Hyalopterus pruni and Hyalopterus amygdali complex. In: Population Structure, Genetics and Taxonomy of Aphids and Thysanoptera. Proceedings International Symposium, Smolenice, Czechoslovakia, 1985. SPB Publishing, The Hague, pp. 370-376.

Berlocher S.H. \& Feder J.L. 2002: Sympatric speciation in phytophagous insects: moving beyond controversy? Annu. Rev. Entomol. 47: 773-815.

Blackman R.L. 1987: Morphological discrimination of a tobacco-feeding form from Myzus persicae (Sulzer) (Hemiptera: Aphididae), and a key to New World Myzus (Nectarosiphon) species. Bull. Entomol. Res. 77: 713-730.

BlaCKMAN R.L. 1990: Specificity in aphid/plant genetic interactions, with particular attention to the role of the alate colonizer. In Campbell R.K. \& Eikenbary R.D. (eds): Aphid-Plant Genotype Interactions. Elsevier, New York, pp. 251-274.

BLACKMAN R.L. 1992: The use of ordination techniques to discriminate within aphid species complexes. In Sorensen J.T. \& Foottit R. (eds): Ordination in the Study of Morphology, Evolution and Systematics of Insects. Elsevier, Amsterdam, pp. 261-275.

Blackman R.L. \& Brown P.A. 1991: Morphometric variation within and between populations of Rhopalosiphum maidis with a discussion of the taxonomic treatment of permanently parthenogenetic aphids (Homoptera: Aphididae). Entomol. Gen. 16: 97-113.

Blackman R.L. \& De BoIse E. 2002: Morphometric correlates of karyotype and host plant in genus Euceraphis (Hemiptera: Aphididae). Syst. Entomol. 27: 323-335.

Blackman R.L. \& Eastop V.F. 2000: Aphids on the World's Crops. An Identification and Information Guide. 2nd ed. John Wiley and Sons, Chichester, 375 pp.

Blackman R.L. \& Eastop V.F. (in press): Taxonomic issues. In van Emden H.F. \& Harrington R. (eds): Aphids as Crop Pests. CAB International, Wallingford.

Blackman R.L. \& Spence J.M. 1994: The effects of temperature on aphid morphology, using a multivariate approach. Eur. J. Entomol. 91: 7-22.

Blackman R.L., Eastop V.F. \& Hills M. 1977: Morphological and cytological separation of Amphorophora Buckton (Homoptera: Aphididae) feeding on European raspberry and blackberry (Rubus spp.). Bull. Entomol. Res. 67: 285-296.

BÖRNER C. \& HeInZE K. 1957: Homoptera in "Handbuch der Pflanzenkrankheiten", Tierische Schädlinge an Nutzpflanzen. Paul Parey, Berlin-Hamburg, 525 pp.

Brown M.B. \& Forsythe A.B. 1974: Robust test for the equality of variances. J. Am. Statist. Assoc. 69: 364-367.

Brown P.A. \& Blackman R.L. 1994: Morphometric variation in the Geoica utricularia (Homoptera: Aphididae) species group on Pistacia (Anacardiaceae), with descriptions of new species and a key to emigrant alatae. Syst. Entomol. 19: 119-132.

Bush G.L. 1994: Sympatric speciation in animals: new wine in old bottles. Trends Ecol. Evol. 9: 285-288.

Clements K.M., Wiegmann B.M., Sorenson C.E., Smith C.F., Neese P.A. \& Roe R.M. 2000: Genetic variation in the Myzus persicae complex (Homoptera: Aphididae): evidence for a single species. Ann. Entomol. Soc. Am. 93: 31-46.

CoYNe J.A. \& OrR H.A. 1989: Patterns of speciation in Drosophila. Evolution 43: 362-381.

Dixon A.F.G. 1998: Aphid Ecology. 2nd ed. Chapman \& Hall, London, $300 \mathrm{pp}$.

EASTOP V.F. 1966: A taxonomic study of Australian Aphidoidea (Homoptera). Austr. J. Zool. 14: 399-592.

EASTOP V.F. 1973: Deductions from the present day host plants of aphids and related insects. In van Emden H.F. (ed.): InsectPlant Relationships. Symposium of the Royal Entomological Society of London 6. Blackwell, Oxford, pp. 157-178.

FISHER R.A. 1936: The use of multiple measurements in taxonomic problems. Ann. Eugen. 7: 179-188.

Futuyma D.J. \& Moreno G. 1988: The evolution of ecological specialization. Annu. Rev. Ecol. Syst. 19: 207-234.

Ilharco F.A. \& van Harten A. 1987: Systematics. In Minks A.K. \& Harrewijn P. (eds): Aphids. Their Biology, Natural Enemies and Control. Vol. A. Elsevier, Amsterdam, pp. 51-77.

Johnson P.A., Hoppenstadt F.C., Sмith J.J. \& Bush G.L. 1996: Conditions for sympatric speciation: a diploid model incorporating habitat fidelity and non-habitat assortative mating. Evol. Ecol. 10: 187-205.

Liou L.W. \& Price T.P. 1994: Speciation by reinforcement of premating isolation. Evolution 48: 1451-1459.

LoXdale H.D \& LuSHAI G. 1998: Molecular markers in entomology. Bull. Entomol. Res. 88: 577-600.

KRZANOWSKI W.J. 1990: Principles of Multivariate Analysis. Clarendon Press, Oxford, 246 pp.

Mackenzie A. \& Guldemond J.A. 1994: Sympatric speciation in aphids. II. Host race formation in the face of gene flow. In Leather S.R., Watt A.D., Mills N.J. \& Walters K.F.A. (eds): Individuals, Populations and Patterns in Ecology. Intercept, Andover, pp. 379-395.

Margaritopoulos J.T., Tsitsipis J.A., Zintzaras E. \& Blackman R.L. 2000: Host-correlated morphological variation of Myzus persicae (Hemiptera: Aphididae) populations in Greece. Bull. Entomol. Res. 90: 233-244.

Margaritopoulos J.T., TzortZi M., Zarpas K.D., Tsitsipis J.A. \& BlackMAN R.L. 2006: Morphological discrimination of Aphis gossypii (Hemiptera: Aphididae) populations feeding on Compositae. Bull. Entomol. Res. 96: 153-165.

Mopper S. \& Strauss S.V. 1997: Genetic Structure and Local Adaptation in Natural Insect Populations. Effects of Ecology, Life History and Behaviour. Chapman \& Hall, New York, 368 pp.

MoRAn A.N. 1986: Morphological adaptation to host plants in Uroleucon (Homoptera: Aphididae). Evolution 40: $1044-1050$

Mosco M.C., Arduino P., Bullini L. \& Barbagallo S. 1997: Genetic heterogeneity, reproductive isolation and host preferences in mealy aphids of the Hyalopterus pruni complex (Homoptera, Aphidoidea). Mol. Ecol. 6: 667-670.

Raymond B., Searle J.B. \& Douglas A.E. 2001: On the processes shaping reproductive isolation in aphids of the Aphis fabae (Scop.) complex (Aphididae: Homoptera). Biol. J. Linn. Soc. 74: 205-215.

SCHLUTER D. 2001: Ecology and the origin of species. Trends Ecol. Evol. 16: 372-380.

Sneath P.H.A. \& Sokal R.R. 1973: Numerical Taxonomy. W.H. Freeman, San Francisco, 513 pp.

Soulé M. \& CouzIN-Roudy J. 1982: Allometric variation. 2. Developmental instability of extreme phenotypes. Am. Nat. 120: $765-786$. 
Spampinato R., Arduino P., Barbagallo S. \& Bullini L. 1988: Analisi genetica di Hyalopterus pruni e $\mathrm{H}$. amygdali e dimostrazione dell'esistenza di una nuova specie (Homoptera, Aphidoidea). In: Atti XV Congresso nazionale italiano di Entomologia. L'Aquila, pp. 261-265.

Stroyan H.L.G. 1984: Aphids - Pterocommatinae and Aphidinae (Aphidini). Handbooks for the Identification of British Insects. Vol. 2. Royal Entomological Society of London, $232 \mathrm{pp}$.

SunNUCKS P. 2000: Efficient genetic markers for population biology. Trends Ecol. Evol. 15: 199-203.

THOMPson J.N. 1994: The Coevolutionary Process. University of Chicago Press, Chicago, 387 pp.
Thorpe R.S. 1983: A review of the numerical methods for recognizing and analyzing racial differentiation. In Felsenstein J. (ed.): Numerical Taxonomy. NATO ASI Series, Vol. G1. Springer, Berlin, pp. 404-423.

Wool D. \& Hales D.F. 1997: Phenotypic plasticity in Australian cotton aphid (Homoptera: Aphididae): host plant effects on morphological variation. Ann. Entomol. Soc. Am. 90: 316-328.

VIA S. 2001: Sympatric speciation in animals: the ugly duckling grows up. Trends Ecol. Evol. 16: 381-390.

Received September 12, 2006; revised and accepted November 13, 2006 